\title{
Improving Nursing Practice through Interoperability and Intelligence
}

\author{
Daniela Oliveira \\ Deparment of Informatics \\ University of Minho \\ Braga, Portugal \\ daniela777@live.com.pt \\ António Abelha \\ Centro ALGORITMI \\ University of Minho \\ Braga, Portugal \\ abelha@di.uminho.pt
}

\author{
Júlio Duarte \\ Centro ALGORITMI \\ University of Minho \\ Braga, Portugal \\ jduarte@di.uminho.pt
}

\author{
José Machado \\ Centro ALGORITMI \\ University of Minho \\ Braga, Portugal \\ jmac@di.uminho.pt
}

\begin{abstract}
Hospital inpatient care compromises one of the most demanding services in health institutions when providing a careful and continuous healthcare assistance. Such demands require constant update of the patients' electronic health record allied with support systems responsible for monitoring their clinical information. In this context, this paper presents a new web platform for daily monitoring of patients, designed to be used by health professionals, especially nurses. The application is based on React, an open-source JavaScript library for building user interfaces. The developed tool incorporates two main features: the real-time visualization of the data, and the storage of the patient's historic during an inpatient care episode. The storage capability allows keeping the data updated among hospital shifts. Moreover, this work also highlights the required adaptability of this platform for each health units inside a hospital center according with its needs.
\end{abstract}

Keywords - Interoperability; Hospital Information System; Healthcare; Nursing Practice;

\section{INTRODUCTION}

In hospital environment, the patient security is one of the major concerns in the health world, in the sense of improving the efficiency of healthcare delivery, and minimizing delays or failures that could lead to other concequences. These consequences can be translated to a considerable portion of clinical errors which can be of several types, depending of the approach taken. In terms of effects, Reason J. in [1] argues that errors can be active, with an immediate or latent impact. Thus, the results can appear in short-term or long-term, respectively. According to Reason, these errors can have different sources, disclosed in Figure.1.

Moreover, James Reason's "Swiss cheese" model of error causation defines that in complex organizations such as hospitals, errors occur due to the holes or flaws in the multiple layers of defense, causing adverse outcomes to the patients [1][2].
The Institute of Medicine's Quality of Health Care in America valued that about 98000 people every year die due to clinical errors at hospitals. Comparing to other main causes of death in the country, this causes a greater impact in the scientific community, becoming one of the most emerging public problems today [3].

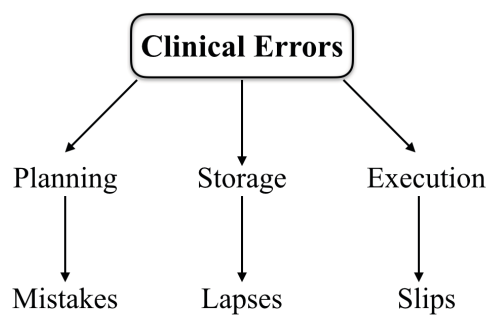

Figure. 1 Classification of clinical errors according to Reason J. [1].

The continuous and dynamic alteration of patients' clinical status in healthcare institutions is one of the major causes of the occurrence of adverse events. This level is very high becoming urgent to find connections with other areas, such as Information Technologies (IT) [4]. This is one of the most explored field in Medical Informatics, raising great challenges in terms of development, implementation and maintenance. Thus, over the years, and due to the high data flow, efficient and user-friendly support systems for health professionals have been emerging, called Hospital Information Systems (HIS) [5].

The high number of professionals involved in clinical acts, combined with their diversity of academic backgrounds, has led to high level of automation of services, from the well-known clinical software, which has several advantages such as financial, administrative, and recruitment, until reaching the medicine itself. There, the role of these developed HIS is crucial [6] [7]. Its main goal is to streamline and support the provision of direct healthcare to the patient, being some of them oriented 
to the use of a certain group of professionals, such as doctors and nurses.

In Europe, the Health2020 strategic program organized by World Health Organization (WHO) highlights nurses and their important role in improving healthcare delivery, since they are the most direct and continuous contact with the patient throughout the hospitalization episode. The essence of nursing is "caring", i.e., providing the highest possible quality care for an assertive practice. As such, these professionals are responsible for providing safe, high quality and efficient healthcare services. To provide this high quality, all the conditions must be attended. Thus, one of the main focuses of this program is the nursing team [8][9].

In order to overcome failures in shifts change, such as administration of a given medication with the wrong dosage or omission of some relevant information about the patient, it emerged the motivation to develop a nursing care support system in the hospitalization. This platform aims to automate information for an easy visualization, excluding the need to resort to other means that would certainly take more time. All the patient's relevant information for nurses can be consulted on this platform, such: the location of his/her room; identification of number of the bed; the type of fasting that is attributed to him with a specific examination or analysis that he/she will carry out; the alerts and medication associated to the patient; among other attributes. This data is updated continuously.

The presented paper is organized as follows: section II describes interoperability among information systems, section III depicts the research methodologies used, section IV and V presents the web platform developed and discusses its relevance, respectively, and section VI discloses the main conclusion outlined with this work.

\section{INTEROPERABILITY}

\section{A. Background}

The presentation of clinical information is done in several ways, depending on the kind of data stored in the systems. For this reason, it often becomes difficult for health professionals to integrate quickly into the patient's condition. For all HIS to operate at their maximum efficiency and to relate to each other without communication failures and with high coherence, the concept of interoperability takes great importance in this context [10].

In the middle of $1960 \mathrm{~s}$, the Healthcare Information and Management Systems Society (HIMSS) emerged a non-profit association, whose mission is to unite efforts to continuously improve health through information technology [11]. Therefore, there will be no better definition of interoperability than the one proposed by it: "Interoperability describes the extent to which systems and devices can exchange data, and interpret that shared data. For two systems to be interoperable, they must be able to exchange data and subsequently present that data such that it can be understood by a user" [12].

\section{B. Interoperability and Case Study}

The main goal of this study is to automate the hospital information, updating it constantly, without any effort or action that might interfere with the process of healthcare delivery. In order for this automation to be possible, it was needed to cross several kinds of information from different sources [13]. This information must be proceeded to create a Data Warehouse (DW). "A data warehouse is a subject-oriented, integrated, time-variant, and nonvolatile collection of data in support of management's decision-making process" - W. H. Inmon [14].

With the DW built, bridges between different HIS, previously non-existent, are established. Some information was transformed and adapted to the project, given the needs of the users of the platform. At this stage of the project, the interoperability between the systems used is guaranteed, reducing some possible communication failures at any level [15].

\section{METHODOLOGIES OF RESEARCH}

In the initial phase of the project, several studies and tests were carried out in order to understand the needs of the project. Afterwards, the results obtained were analyzed for a later validation of the best model and architecture. Two methodologies and three research techniques were used, as will be presented.

\section{A. Case Study}

A Case Study (CS) is a methodology which contributes to the definition of research topics, for a given context. Among several methodologies used in Information Systems, the CS was chosen for the definition of the project, given its highlight among other strategies, especially in the organizational context.

Pozzebon and Freitas [16] claimed that the researcher must define clearly the initial goals and the reason of the choice of the research target, and describe in detail the techniques and sources used for the analysis and collection of data, avoiding some common mistakes detected in the application methodology. Additionally, the researcher must be impartial, ignoring his/her personal opinions that can interfere with the results. Moreover, according to Benbasat et al. [17], CS has as main characteristic the versatility, which can be used in distinct approaches. Thus, they defined the follow eleven points, that will be respected in this work:

- The object of study is evaluated in its natural context.

- The collection data is performed in several ways.

- A few entities are analyzed (groups, persons or organizations).

- The complexity of the unit is studied intensively;

- CS are more suitable for exploration, classification and definition of several stages of developing, being a process of knowledge. 
- The research stage does not include control or experimental manipulation.

- The independent and dependent variables might not be defined a priori.

- The results are dependent of the type of integration.

- During the gathering of hypotheses, changing types can occur (local or methods of collecting data)

- CS is suitable to respond questions like "how" and "why".

- The main focus lies in real and actual happenings.

\section{B. Design Science Research}

The Design Science Research (DSR) model used was the one proposed by Peffers [18] with the following structure:

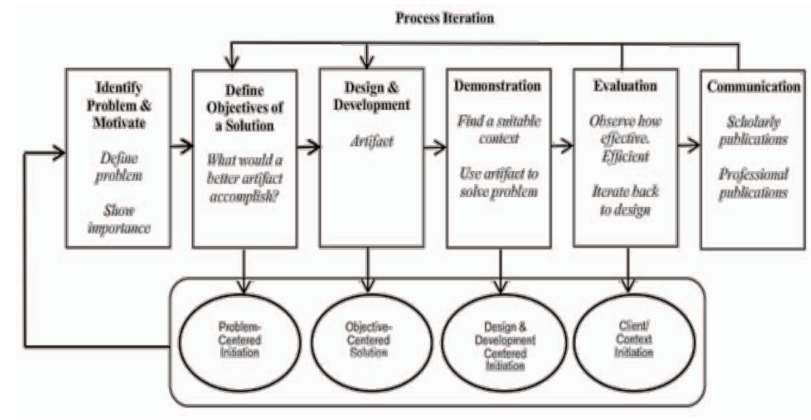

Figure. 2 DSR Methodology Process Model [19].

The starting point was the identification of the problem. The problem that arises is how the whole relevant clinical information of each patient at the time of hospitalization can be provide at same place. This information is dispersed by several systems and can be storage in several ways. The goal is to find a solution to the above problem, which helps health professionals to have access to the information they need at a given moment, in a fast and intuitive way. Thus, the chosen solution was to develop an artefact capable of showing all the necessary and constantly updated information about each patient. This artefact in production will be subsequently implemented, firstly in the Cardiology health unit of the Hospital Center of Oporto (CHP). Afterwards, the next goal is the its propagation to the remaining units. After its implementation, its impact will be reassessed by the users with specific models.

\section{Techniques of research}

To follow the aforementioned methodologies, it was needed the use of researcher techniques through the processes of search and collection of data.

\section{1) Literature review}

An exhaustive bibliographic analysis was carried out in search of similar existing projects. This stage is very important in all research projects, not only for a better definition of the case study, but also to understand with greater precision the developments of the subject in question, at the present time. According to Cardoso [20], all investigators must in detail analyze the work of others who proceeded and only after that, proceed to their own adventure. The constant evolution of science must be taken into account.

A good review leads to an easier delimitation of the problem under study and to the discovery of new lines of investigation, avoiding possible repetitions and proposing future goals.

No support platform for hospital inpatient care was found, with specifications that will be described later. However, there are several developments in this area, such as the hospital management system [21], which consists of the classification of patients in different degrees of care (minimum, intermediate, high dependency, semi-intensive and intensive) for organization of appropriate care and sizing of the required nursing professionals.

2) Interviews

The interviews are a relevant technique in the research process. The involvement of future users provides an accurate feedback about their needs.

The researcher can feel the reality and clarify the objectives, the structure that intends to follows during the interview and the its goal, earning the trust of the interviewing to assure its collaboration in the future [22].

To accomplish these stage, several visits to the health unit of Cardiology of CHP were done, more precisely, to the nursing room. The chef-nurse was the main person interviewed, who showed great collaboration and interest in the proposed platform. During the interviews, it was reported the major difficulties that nurses from that unit feel daily and discussed the main strategies to outcome such problems.

\section{3) Questionnaires}

The questionnaires technique is very similar to the interviews with the difference that the interviewer does not has direct contact with the interviewing, and they answer the questionnaire anonymously. Regarding the type of questions, the researcher must be careful since they should be clear, coherent and with maximum neutrality [23].

In the first phase of the project, a questionnaire with eight questions was carried out. The group of interviewees where some nurses from the cardiology department, with a final result of 35 questionnaires answered.

Objectivity and simplicity were concerns taken into account when the questions were constructed, aiming to understand the main failures that respondents have in their workplace. Among the eight questions addressed, four were highlighted: 
a. Question 3: Have you ever faced with the possibility of complications of the patient's condition due to information system failures?

b. Question 6: Have you ever faced with communication failures, particularly in the absence of records from the previous shift?

c. Question 7: Have you ever had difficulty accessing the updated patient's clinical process?

d. Question 8: In your opinion, it would be appropriate the support of the new technologies to the daily provision of health care in your unit?

The questionnaires were handled one by one through Tableau Software, a tool that allows you to organize and interpret data, easily answering questions. The data entered in the data source were of the nominal type. Thus, the value 0 was used to "No" answers and the value 1 to answers "Yes".

In order to facilitate the analysis and understanding of the data, the results are presented as a percentage. The answers to four of the eight questions in the questionnaire, can be found in figure 3 .

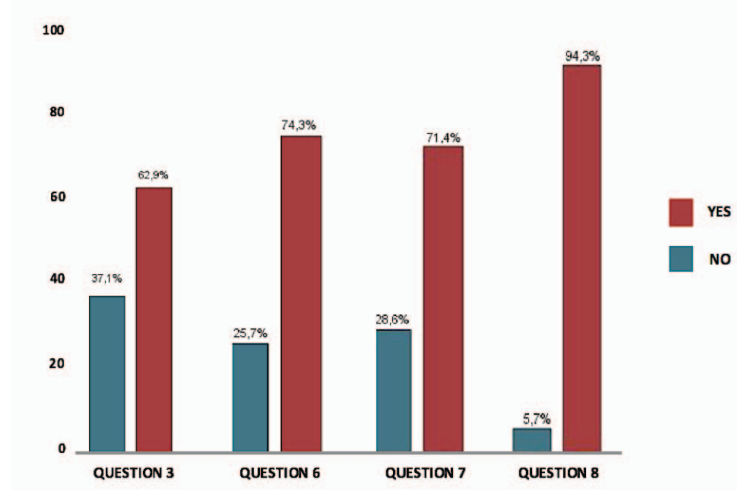

Figure. 3 Result of the answers to the four questions in the questionnaire analyzed.

The interpretation of the results led to several of the initial motivations of the project being strengthened and reinforced. The idea that the support of the new technologies in the provision of healthcare in a hospital unit is fundamental. The need of integration and interoperability between systems, devices and health professionals is vital.

\section{Nursing Practice SupPort System}

The support system for nursing practice in an inpatient setting aims to help the health professional, in this case nurses, in real time. Nurses should obtain a more quick and effective access to all kinds of useful information about the patients and their tasks and actions at their health department. In addition, the application has a repository component that can be accessed at any time, called Patient History. Here each patient will have all their detailed information from the beginning of their hospitalization. The Patient's History was built according to the results obtained in the questionnaires mentioned above, it is very important for the process of nurse shifts. This feature ensures that no information is lost and is visible for all health professionals.

\section{A. Characteristics}

The main characteristics of the Nursing Practice Support System are described below:

I. Frequency of Data Update

- Minimum: Day to day;

- Maximum: 5 to 5 min.

II. Usability

- Real-time updated patient information;

- Simple and effective organization of information, making it easy to perceive and consult;

- Alerts of future events, in particular, analyzes and examinations for executing or changing medications and types of diets, of each patient;

- Easy location of inpatient in the health unit;

- Availability of the daily tasks of nurses in their healthcare department.

\section{Information Content}

- Medication administration;

- Upcoming Examinations;

- Upcoming Analyzes;

- Diagnostic;

- Type of Diets;

- Location of patient in Department;

- Daily Nursing Tasks;

\section{B. Data Sources}

The information in the support system for nursing practice during hospitalization comes from different types of data sources:

- Electronic Nursing Record;

- Electronic Health Record;

- Agency for the Integration, Diffusion and Archiving of Clinical Information;

- Drugs System; 


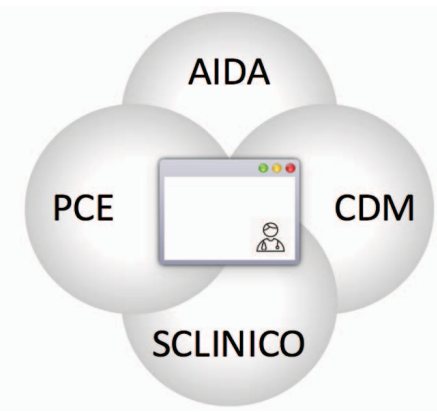

Figure. 4 Relational schema among the different HIS used for the construction of DW.

In order for this project to be possible, there was a need to gather information from several HIS. Consequently, it was developed a process capable to execute all the phases of Extraction, Transformation and Loading (ETL) of the information in an autonomous way.

This new system of support to hospitalization has as main features the high interoperability existing between the aforementioned systems. Thus, the system avoids that during its tasks the health professional must manually access each one of these systems.

\section{DISCUSSION}

The support system for inpatient nursing practice is a project under development. It was previously discussed and approved by clinical leaders of the healthcare institution and later by health professionals who will be their future users. Through this new system, the information is getting available in real-time. For this, it is used autonomous agents to constantly execute ETL processes. The update frequency depends on the refresh rate associated with each kind of data.

The fact that the system presents only the most relevant information, in the most succinct and assertive way as possible, confers to the application a high level of security and, consequently, a high confidence in the presented solution.

The major advantages of this project are:

- Improving quality of health record by the health professionals;

- Improving quality of the data, from its collection to its processing and validation;

- Increasing of the number of relevant information about the patient in same place;

- Easing access of information (easy reading and interpretation).

The first implementation and testing phase of the prototype was carried out at the CHP hospital, which demonstrated the feasibility of the solution.

\section{CONCLUSION}

Increasingly, the use of new technologies for providing better healthcare is emerging. In this context, the proposed system aims to contribute for improving the patient's healthcare quality. Thus, the solution focuses on the patient and his wellbeing, reducing the possibility of the exposure to clinical error. The health professionals seem to be enthusiastic and confident with the solution. They have the awareness that the solution can be of great impact in their daily work.

The main motivations for this project regarding the results obtained in the questionnaires performed to health professionals were the decrease of the probability of clinical error or adverse events; and the creation of interoperability bridges between the several HIS holders of the different kinds of gathered information.

As future work, this application can be extended to other health departments of the hospital, suffering adaptability depending on the requisites of each service. Another improvement will be its portability to mobile version, where health professionals will be able to consult it using a Smartphone or a Tablet with different operating systems. The system also will be a target of several studies of usability and technology acceptance. In the next few steps, the interface can undergo some improvements.

\section{ACKNOWLEDGMENT}

This work has been supported by Compete POCI-01-0145FEDER-007043 and FCT - Fundação para a Ciência e Tecnologia within the Project Scope UID/CEC/00319/2013.

\section{REFERENCES}

[1] Reason, J. (2000). Human error: models and management. Western Journal of Medicine, 172(6), 393.

[2] Machado, J., Abelha, A., Novais, P., Neves, J. and Neves, J., Quality of service in healthcare units, Int. J. Computer Aided Engineering and Technology, Vol. 2, No. 4, pp.436 to 449, 2010.

[3] Donaldson, M. S., Corrigan, J. M., \& Kohn, L. T. (Eds.) (2000). To err is human: building a safer health system (Vol. 6). National Academies Press.

[4] Peixoto, H., Santos, M., Abelha, A. and Machado, J., Intelligence in Interoperability with AIDA, 20th International Symposium on Methodologies for Intelligent Systems, 2012 World Intelligence Congress, Macau, Springer, LNCS Volume ${ }^{\circ}$ 766, 2012.

[5] Coiera, E. (2003). Guide to Health Informatics (2nd ed). London: Hodder Arnold.

[6] S. Khodambashi (2013). Business Process Re-engineering Application in Healthcare in a Relation to Health Information Systems, Procedia Technology, vol. 9, no. 2212, pp. 949-957.

[7] Machado, J., Alves, V., Abelha, A. and Neves, J.; Ambient Intelligence via Multiagent Systems in Medical arena; International Journal of Engineering Intelligent Systems, Special issue on Decision Support Systems; vol. 15, n.3, pp. 167-173, 2007 (SCIMago 2007 SJR 0.19-Q3) (ISI 2007-JCR 0.034 Q4) ISSN: 14728915

[8] World Health Organization (2015). European compendium of good practices in nursing and midwifery towards Health 2020 goals. 
[9] Duarte, J., Portela, F., Abelha, A., Machado, J., Santos, M., Electronic Health Record in Dermatology Service, Communications in Computer and Information Science, 221 CCIS (PART 3), Springer, 2011.

[10] Cardoso, L., Marins, F., Portela, F., Santos, M., Abelha, A., Machado, J. The Next Generation of Interoperability Agents in Healthcare. Int. J. Environ. Res. Public Health 11, no. 5: 5349-5371, 2014.

[11] Amorim M., Miranda F., Duarte J., An approach for the semantic interoperability of SNOMED: Improving quality of health records in Applying Business Intelligence to Clinical and Healthcare Organizations, IGI Globals, 2017.

[12] What is interoperability? http://www.himss.org/library/interoperabilitystandards/what-is-interoperability (Visited on 24/04/2017).

[13] Abelha A., Analide C., Machado J., Neves J., Santos M., Novais P., Ambient Intelligence and simulation in health care virtual scenarios, in Establishing the Foundation of Collaborative Networks, CamarinhaMatos L. Afsarmanesh H., Novais P., Analide C., (Eds), Springer-Verlag, ISBN: 978-0-387-73797-3, pp 461-468, 2007

[14] W. H. Inmon., John Wiley (1996) Building the Data Warehouse.

[15] Duarte, J., Salazar, M., Quintas, C., Santos, M., Neves, J., Abelha, A. and Machado,J. Data Quality Evaluation of Electronic Health Records in the Hospital Admission Process, 9th IEEE/ACIS International Conference on Computer and Information Science, ICIS 2010
[16] Pozzebon, M. and Freitas, H. (1998). Pela aplicabilidade - com um maior rigor cientifíco - dos estudos de caso em sistemas de informação. Revista de Administração Contemporânea, 2(2):143-170.

[17] Benbasat, I., Goldstein, D., and Mead, M. (1987). The case research strategy in studies of information systems. MIS Quarterly, 1(3):220 - 247.

[18] K. Peffers, T. Tuunanen, M. A. Rothenberger, and S. Chatterjee, (2007). A design science research methodology for information systems research, Journal of management information systems, vol. 24, pp. 45-77.

[19] Bendavid, Y., Wamba, S. F., \& Lefebvre, L. A. (2006). Proof of concept of an RFID-enabled supply chain in a B2B e-commerce environment. In Proceedings of the 8th international conference on Electronic commerce: The new e-commerce: innovations for conquering current barriers, obstacles and limitations to conducting successful business on the internet (pp. 564-568).

[20] Cardoso, T., Alarcão, I., and Celorico, J. (2010). Revisão da literatura e sistematização do conhecimento. Porto Editora, Porto, Portugal.

[21] Bento, D. G., Costa, R., Luz, J. H. D., \& Klock, P. (2017). WASTE MANAGEMENT OF HEALTHCARE SERVICES FROM THE PERSPECTIVE OF NURSING PROFESSIONALS. Texto \& ContextoEnfermagem, 26(1).

[22] Lavrakas, P. (2008). Encyclopedia of Survey Research Methods. SAGE Publicationse, Inc.

[23] Williams, C. (2007). Research methods. Journal of Business and Economic Research, 5(3):65-71 